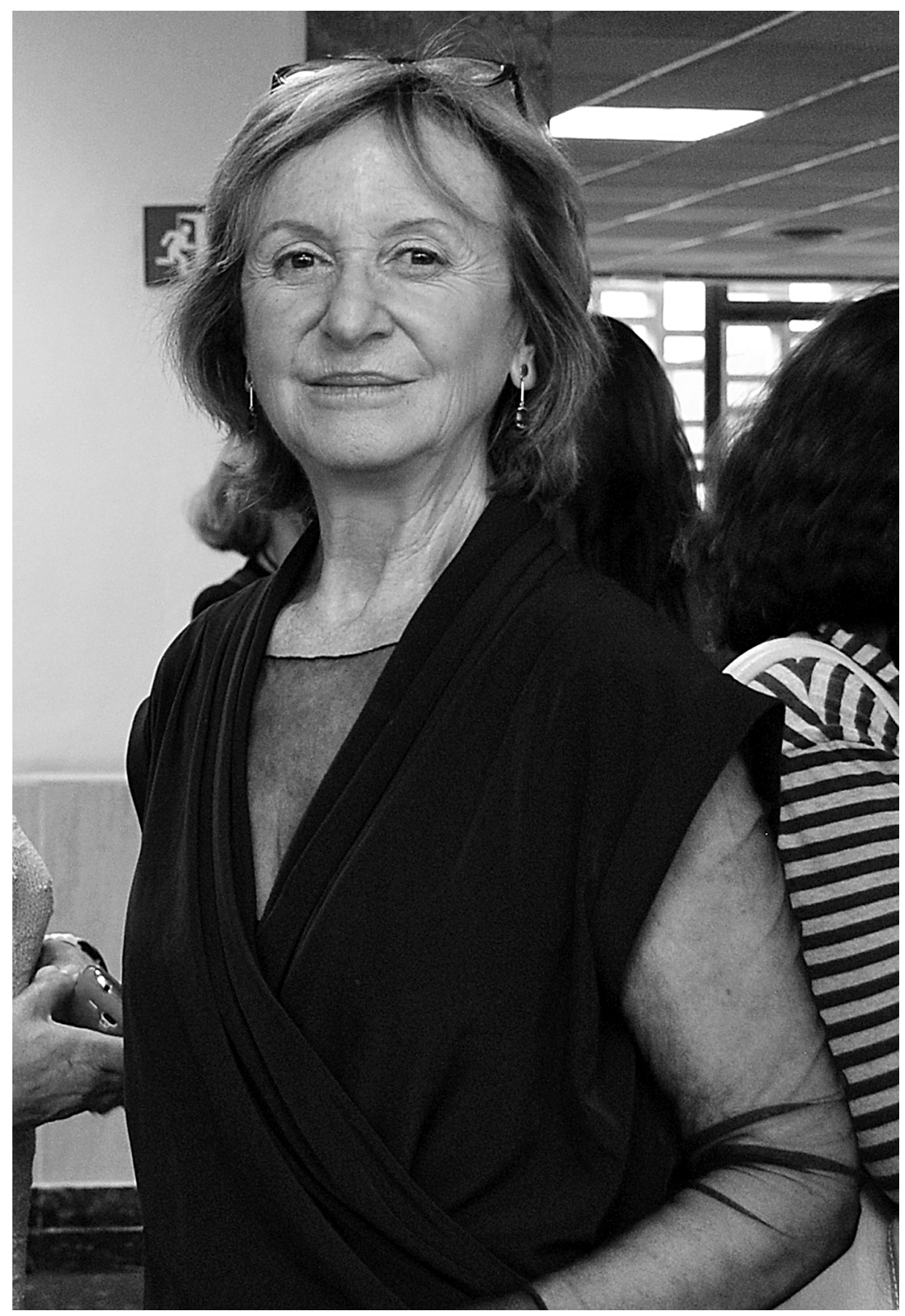




\title{
HOMENAJE A CARMEN ARANEGUI GASCÓ
}

\author{
Vanessa Albelda y Antonio Vizcaíno \\ Departament de Prehistòria i Arqueologia \\ Universitat de València
}

Cualquier persona que se proponga hablar de Carmen Aranegui se encuentra, como mínimo, ante una gran responsabilidad. Más todavía cuando los que suscriben estas palabras se encuentran en el inicio de sus carreras profesionales y no están en disposición de hablar desde la perspectiva que otorga la experiencia. Sin embargo, los reconocimientos más sencillos a veces son los más emotivos, y desde luego nosotros, como últimos doctorandos de Carmen, hablamos desde la más profunda admiración y desde la proximidad que nos ha brindado el haber compartido unos pocos pero intensos años de trabajo junto a ella. Las palabras que siguen constituyen un humilde homenaje de parte de quienes consideramos que, aunque los hechos hablan por sí solos, las trayectorias ejemplares requieren de un reconocimiento. Nos gustaría pensar, además, que con este texto hablamos en nombre de muchas de las personas que han tenido la feliz fortuna de toparse con Carmen a lo largo de su carrera académica, y en especial de nuestros compañeros del Departament de Prehistòria i Arqueologia de la Universitat de València. Esperamos que también ellos reconozcan aquí algunas de las muchas cualidades que caracterizan a la homenajeada y que tantas veces habrán podido constatar a través del trabajo y la convivencia con ella.

Los que la conocemos sabemos que Carmen es una de esas personas que conjugan una faceta profesional impecable con una amabilísima vertiente humana, que la desprovee de ese aura de reverencia que a menudo convierte en intocables a las personas importantes. Cuando uno tiene ocasión de conversar distendidamente con ella, siente el privilegio de quien está junto a una persona de conocimientos vastísimos y con la que resulta imposible no estar permanentemente aprendiendo. Pero también percibe la confidencialidad de alguien que no duda en mostrarse cercana cuando se supera la cordialidad inicial. A pesar de que nuestro primer contacto con Carmen tuvo lugar en calidad de profesora-alumnos durante el último año de licenciatura, en las clases de la ya desaparecida asignatura Arqueología Ibérica, realmente tuvimos ocasión de empezar a conocerla tras terminar la carrera e iniciar los estudios de doctorado. Fue nuestro interés por los iberos el que nos animó a concertar una primera cita con ella en su despacho, que tan familiar ha acabado siendo para nosotros, con el propósito de definir dos trabajos de investigación que ofreciesen nuevas perspectivas sobre algunas de las líneas de trabajo desarrolladas desde el Departament. La elección no fue casual, pues Carmen es una figura de referencia en la investigación del mundo ibérico y a ella debemos algunas de las grandes aportaciones de las últimas décadas en el conocimiento de esta cultura.

Si bien de sus estudios se ha nutrido en conjunto la Arqueología ibérica a nivel estatal, no podemos menos que destacar lo que ha significado y significa para la Arqueología valenciana. En efecto, su brillante trayectoria científica y su capacidad de crear equipo han tenido a bien convertirla en una pieza indispensable, garante de la continuidad de una reconocida escuela de iberistas arraigada en Valencia. Una escuela cuyos orígenes hay que 
buscarlos en la estrecha colaboración establecida entre el antiguo Laboratorio de Arqueología de la Universitat de València (1924) y el Servei d'Investigació Prehistòrica de la Diputació de València (1927), y que estuvo muy influenciada por la escuela catalana, con Pere Bosch Gimpera a la cabeza. Carmen aprendió de los grandes en un momento álgido de la investigación ibérica en el País Valenciano, y trabajó codo con codo junto a algunas de las figuras que marcarían el futuro de esa tradición. Los contactos con personalidades de la talla de Domingo Fletcher (1912-1995) y Enrique Pla (1922-1988) en el SIP, así como la estrecha relación tejida con el maestro Miquel Tarradell (1920-1995) y sus discípulos Gabriela Martín (1935), Milagro Gil-Mascarell (1941-1994) y Enrique Llobregat (1941-2003), son esenciales para comprender la trayectoria de Carmen, quien ha sabido transmitir a las posteriores hornadas de investigadores los conocimientos y la dedicación fruto de ese contacto. Carmen representa, en efecto, ese precioso nexo de unión entre las grandes figuras del iberismo valenciano y las nuevas generaciones incorporadas a partir de los años 80, y desde luego ha sabido conjugar lo mejor de cada parte, asumiendo las formas, el talante y los conocimientos de los grandes, pero adaptándose como nadie a los nuevos planteamientos teóricos, las nuevas tecnologías y las visiones de los más jóvenes.

De su capacidad de renovación y actualización ha dado buena cuenta en las distintas líneas de trabajo que ha venido desarrollando desde que se licenciase en Filosofía y Letras, sección de Historia, en 1967. Sus primeras incursiones en la investigación arqueológica vinieron de mano de los estudios ceramológicos tanto de época ibérica como romana, un ámbito que, como ella misma ha reconocido en alguna ocasión (Aranegui 2014), era el más habitual entre las todavía escasas mujeres que decidían aventurarse, no sin obstáculos, en el mundo de la investigación académica. Así, con su memoria de licenciatura Las cerámicas grises de tipo ampuritano en la región valenciana (1968) abordó la problemática de la dispersión y comercialización de esta particular producción cerámica. A partir de este trabajo desarrolló una investigación de mucho mayor calado sobre las cerámicas ibéricas y su análisis formal y funcional, que quedaría plasmada en la tesis doctoral La cerámica ibérica en la región valenciana (1972), dirigida por Tarradell. Ha sido este un tema que nunca ha dejado de tratar, prestando especial atención a las producciones edetanas con decoraciones complejas. Y, lo más importante, lo ha hecho siempre adoptando perspectivas analíticas e interpretativas novedosas. Carmen, como ya hiciese Tarradell, adoptó la mirada antropológica para ahondar en el contexto social y cultural que daba sentido a estas producciones, y lo hizo a pesar de que en los años 60 y 70 el auge de la historia económica había dejado en un segundo plano el estudio de la plástica. A través de ese nuevo enfoque, se abrió un prometedor pero complejo campo de estudio para el que se hizo necesario el acercamiento a otras disciplinas, un denso conocimiento teórico sobre las representaciones icónicas y el manejo de referentes de otras culturas antiguas, pero también un exhaustivo análisis del registro arqueológico, algo que ella supo y sigue sabiendo hacer con solvencia. La Arqueología ibérica, que hasta el momento se mostraba poco fértil en estos temas, experimentó con sus trabajos y los de otros compañeros tanto del Departament y del SIP como de otros centros de investigación, un notable desarrollo y una nueva manera de aproximarse al imaginario de las élites ibéricas. De ello queda constancia en Damas y caballeros en la ciudad ibérica (1997), una obra de referencia que firma junto a Consuelo Mata y José Pérez Ballester, así como en numerosos artículos de publicaciones especializadas y en proyectos de investigación como Imagen, mito y sociedad en la Cultura Ibérica (1991) y Los Iberos a través de su cerámica (1995). 


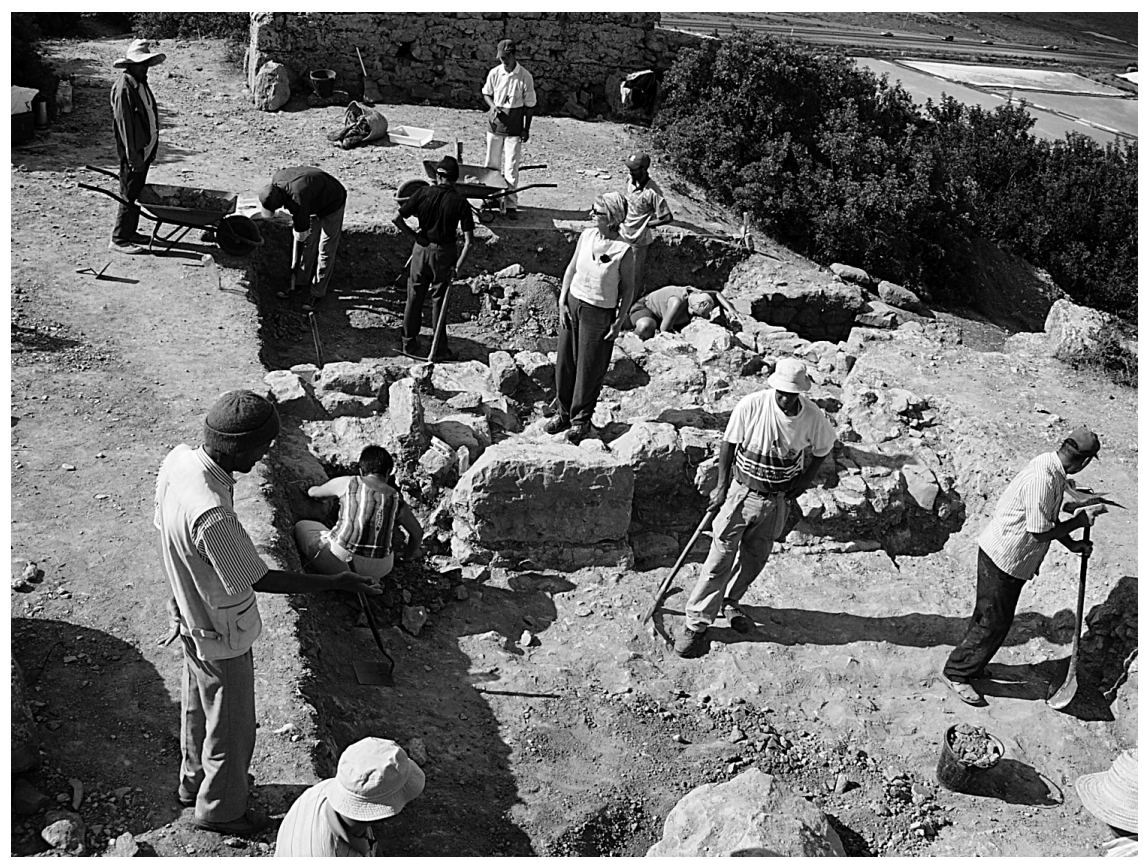

El estudio de la iconografía ibérica también le ha llevado a tratar otros formatos artísticos como la escultura en piedra y la coroplastia ibéricas, pero siempre bajo la premisa de otorgar el protagonismo al trasfondo social que les da sentido, superando así las descripciones estilísticas y las clasificaciones tipológicas a las que con frecuencia se han limitado los estudios iconográficos. A través de estos planteamientos ha incidido en las transformaciones derivadas del paso de una sociedad de carácter principesco, en la que el poder aristocrático se reconocería en las esculturas de gran formato vinculadas a los monumentos funerarios, a una sociedad en las que los oppida se convierten en sede de unas elites menos poderosas pero igualmente interesadas en manifestar su poder a través de objetos de prestigio, como las cerámicas decoradas. Todo ello sin dejar de tener en consideración las propias variables geográficas de este fenómeno.

En este mismo sentido, una de las vías prioritarias de estudio desarrolladas por Carmen ha sido la de los procesos de formación y disgregación de la cultura ibérica, para lo cual ha abordado con perspectiva un amplio margen cronológico y geográfico, adoptando unas visiones holísticas de las que ella siempre se ha mostrado partidaria, en especial en un momento como el actual en el que la investigación arqueológica tiende a la hiperespecialización. En este campo, sus trabajos han abogado por la superación de las teorías coloniales, tan presentes en la interpretación arqueológica del siglo XX, y por la consiguiente afirmación del papel activo de las comunidades indígenas en el proceso de formación de la cultura ibérica, lo que ha supuesto sustituir la concepción tradicional de la superioridad 
greco-fenicia por la idea del diálogo y la hibridación como vía más factible para entender los procesos de génesis cultural.

La consideración del contacto comercial con otros pueblos peninsulares y mediterráneos para entender estas transformaciones ha sido esencial en sus investigaciones. El interés por las rutas comerciales como vías de intercambio de productos, pero también de ideas, lo ha centrado en el litoral valenciano, particularmente en el sucronensis sinus. Las míticas costas de la Marina Alta, con los referentes geográficos del Cap de la Nau y el Cap de Sant Antoni, tan ligados a las citas literarias de los clásicos, y el Montgó como espacio sacralizado por los enterramientos de tesoros ibéricos; la desembocadura del Xúquer como punto de encuentro entre la Contestania y la Edetania, y la problemática en torno a Sucro; o el tráfico comercial a través de La Albufera y el golfo de Valencia, han sido algunos de los espacios que más ha trabajado. Sin embargo, su verdadera niña mimada ha sido desde siempre Sagunto. Carmen acogió con gusto el relevo de las excavaciones de Sagunto en 1974 por consejo de Fletcher, lo cual no deja de ser trascendental dado que en aquellos momentos no era tan habitual que la dirección de una excavación arqueológica estuviese en manos de una mujer, y menos todavía de una mujer joven. Asumir la responsabilidad de dirigir con tan solo veintinueve años una excavación tan destacada como la del Grau Vell -con los obstáculos inherentes a lo que era considerado por muchos en Sagunto como una innecesaria injerencia del cap i casal-y crear un equipo de trabajo del que Carmen guarda un grato recuerdo, no solo ha revestido al yacimiento y a Sagunto de un importantísimo componente sentimental para ella, sino que ha acabado marcando su propia carrera académica. De hecho Sagunto sigue estando hoy entre sus prioridades. De la Arse ibérica han sido cruciales sus trabajos para documentar las estructuras del puerto a través de numerosas campañas de excavación (1974-2004) y para conocer el sistema defensivo del antiguo oppidum. De la Saguntum romana debemos reseñar sus contribuciones al conocimiento del foro y del teatro (1983-2002) y a la reafirmación de la importancia de este municipium en los intercambios comerciales y en el proceso de romanización en tierras valencianas, ideas que han quedado recogidas en obras de gran calado como Saguntum y el mar (1991) y Sagunto, oppidum, emporio y municipio romano (2004).

No hay duda de que Carmen se ha convertido en la mayor especialista, tanto de época ibérica como romana, del área saguntina, gracias a un intenso trabajo de campo. Sin embargo, ello no debe hacernos olvidar que ha sido directora y codirectora de excavaciones en otros puntos de la geografía valenciana, como las de El Cabezo Lucero (Guardamar del Segura, Alicante, 1980-1986), el Penyal d'Ifac (Calp, Alicante, 1974 y 1976), El Passet de Segària (Benimeli, Alicante, 1977) o la Cueva del Sapo (Chiva, Valencia, 1984).

Pero ha sido fuera de esas fronteras donde ha llevado adelante uno de sus proyectos más queridos: Lixus. Si Sagunto es su niña mimada, no menos importante ha sido este yacimiento marroquí, que se ha convertido en uno de sus grandes logros profesionales. Hacerse cargo en 1995 de la dirección del proyecto que había iniciado Tarradell a finales de los 40 y relanzado el prematuramente fallecido Prof. M. Fernández Miranda (1946-1994), supuso una carrera de fondo que requirió arrojo, tenacidad y una gran capacidad diplomática para superar los no pocos obstáculos burocráticos que planteó el contexto marroquí, especialmente -de nuevo- para una mujer. La continuidad del proyecto hasta 2009 y su permanencia como directora del mismo ponen de manifiesto, sin embargo, que los proble- 
mas los superó con éxito gracias a su diligencia y, sobre todo, a sus cualidades humanas, esenciales para construir un sólido equipo como ha sido siempre el de Lixus. Nosotros tuvimos la suerte de entrar a formar parte del mismo en la campaña de 2009. Y la guardamos en el recuerdo como una experiencia fantástica que, sin lugar a dudas, supuso un momento de inflexión en nuestra relación con Carmen, pues al vínculo académico que habíamos tejido hasta el momento se sumó la vertiente más humana, más próxima. Y no porque no la hubiese mostrado antes en su día a día en la universidad, sino porque las aventuras y desventuras de un viaje por las sorprendentes tierras marroquíes, la convivencia, las charlas a media noche bajo el cielo estrellado de Larache, los desayunos a primera hora -en los que siempre era ella la primera en aparecer y nos esperaba con una sonrisa y acompañada de un té, un queso fresco, unas bayas de goji y un zumo de limón- y sus enseñanzas en todo tipo de materias, acaban dejando una huella profunda. Allí pudimos conocer de primera mano a esa Carmen que nunca pierde el ritmo, que siempre muestra buenas maneras y que con su vitalidad es capaz de llevar a todo el grupo adelante. Y, por supuesto, pudimos aprender de la complejidad de una ciudad como Lixus, fértil en niveles fenicios, púnicos, mauritanos y romanos, y su relación con los circuitos comerciales del Estrecho de Gibraltar, un lugar que ella valora especialmente, como bien nos hizo saber mientras lo surcábamos desde el aire rumbo a Tánger.

Además de su buen hacer en el trabajo de campo, la excelencia científica de Carmen ha venido avalada por una intensa actividad desplegada en distintos ámbitos de la investigación científica, enriquecida, además, por su estancia en centros de prestigio internacional, como el Centre Camille Jullian de la Université de Provence 3 en Aix-enProvence (1980 y 1996), la Escuela de Historia y Arqueología de la Academia de España en Roma (1986, 1992), el Institut d'Art et d'Archéologie de la Université de París-Sorbone 1 (1997), la Maison de l'Archéologie \& de l'Ethnologie René Ginouvès de París (1997) o la Universidad Estatal de Pernambuco (2003). Su participación ha sido señalada en comités científicos de gran reconocimiento (Institut d'Arqueologia i Prehistòria de la Universitat de Barcelona desde 1984; miembro corresponsal de los Deutschen Archaologischen Instituts desde 1990; UMR 154 'Société de la protohistoire et de l'antiquité en France méditerranéenne' del Centre National de la Recherche Scientifique de Francia, 1998-2002; Consejo Asesor del Centro Andaluz de Arqueología Ibérica de Jaén desde 1998; miembro del comité científico del Parque Arqueológico del Mundo romano de la Xunta de Galicia desde 2004; Institut Català d'Arqueologia Clàssica desde 2013), así como en numerosísimos congresos de carácter nacional e internacional, en comités de redacción de revistas de Arqueología (Fonaments, Anales de Arqueología Cordobesa, Iberia. Revista de la antigüedad, Pallas, Pasajes, Tabona, Saguntum-PLAV) y en la dirección tanto de proyectos de investigación competitivos como de tesis doctorales en diferentes universidades españolas.

Pero para comprender la trascendencia de su trabajo, no podemos limitarnos a contemplar su actividad en el ámbito estrictamente académico. Consciente de las responsabilidades públicas que deben ser inherentes a los profesionales de la Arqueología, Carmen se ha implicado de manera directa en la gestión del patrimonio arqueológico, asumiendo cargos de importancia en la administración pública. Así, entre los años 80 y 90 estuvo vinculada a la Conselleria de Cultura de la Generalitat Valenciana como jefa de servicio de la Direcció General de Patrimoni (1986-1988), como miembro del Consejo 
Asesor de Arqueología (1987-1995) y como consellera de número de la desaparecida Institució Valenciana d'Estudis i Investigació (IVEI) (1994-1998). Pero también trabajó a nivel estatal en calidad de miembro asesor por la Comunitat Valenciana del Consejo del Patrimonio Histórico Español del Ministerio de Cultura (1987-1988) y de vocal de la Junta Superior de Excavaciones y Exploraciones Arqueológicas del Ministerio de Cultura (1994-1998). De su época de trabajo en la administración pública quizá haya sido la polémica restauración y rehabilitación del teatro romano de Sagunto el episodio de mayor trascendencia o, al menos, el de mayor impacto. Independientemente de las suspicacias que ha despertado y sigue despertando, en gran medida auspiciadas por enfrentamientos políticos que supieron recurrir con maestría al oportunismo político, el proyecto tuvo un objetivo concreto y meritorio en el que Carmen siempre ha creído: devolver a los saguntinos un espacio emblemático y dotarlo de uso, convirtiéndolo en un espacio vivo y de gran capacidad didáctica - pocos teatros romanos evocan la volumetría real como lo hace el de Sagunto- rehuyendo la tan habitual idea romántica de la ruina arqueológica entendida como objeto de veneración. A pesar de las buenas intenciones, las injerencias políticas acabaron envenenando el proceso, lo cual fue francamente nocivo para el propio desarrollo de los proyectos de investigación y para la puesta en valor del rico patrimonio saguntino.

Tampoco podemos olvidar, si continuamos hablando de esa vertiente pública de su trabajo, la importantísima labor divulgativa que Carmen ha realizado a lo largo de su carrera. Entender que la producción de conocimiento científico debe traspasar las fronteras de la Academia y llegar a la sociedad ha sido un precepto más que asimilado por ella. Muchos recordarán la exitosa exposición Los Iberos. Príncipes de Occidente (1997) que supuso un hito en la proyección internacional de la cultura ibérica y un redescubrimiento de la misma a nivel estatal. Como comisaria por parte de España, Carmen, junto al resto del equipo, demostró un claro interés por ofrecer una visión renovada y actualizada de los iberos y por situarlos entre las culturas más atractivas del Mediterráneo antiguo. Y así fue, pues la exposición viajó por lugares de referencia cultural a nivel europeo como el GrandPalais (París, 1997-1998), el Kunst- und Ausstellungshalle der Bundesrepublik Deutschland (Bonn, mayo-agosto de 1998) y la Fundación La Caixa (Barcelona, octubre-diciembre de 1998), y representó un punto álgido en la popularización del mundo ibérico en un año en que, además, se conmemoraba el centenario del descubrimiento de la Dama de Elche. A pesar de que Carmen ya había intervenido en la organización de otras exposiciones como La cultura ibérica (1983) en el Museu de Prehistòria de València, el caso de Los Iberos. Príncipes de Occidente constituyó un verdadero reto, y a ella siguieron otras de menor proyección pero también importantes, como Argantonio rey de Tartessos (2000) promovida por la Fundación El Monte (Sevilla) y expuesta en el Museo Arqueológico Nacional de Madrid (MAN) y en el Museo Arqueológico de Alicante (MARQ), y Opulentissima Saguntum (2003-2004) impulsada por la Fundació Bancaixa en Sagunto. A su incursión en el mundo de las exposiciones habría que sumar su habitual participación en revistas de divulgación histórica para el gran público, así como toda una serie de actividades (excursiones, charlas, presentaciones) que contribuyen a difundir el conocimiento sobre el patrimonio arqueológico.

Su más reciente gran aportación a la divulgación del pasado ibérico ha sido el libro Los iberos, ayer y hoy. Arqueologías y culturas (2012) editado por Marcial Pons. Una obra sin 
duda necesaria que ha venido a cubrir un vacío, pues a pesar de que la cultura ibérica sigue siendo atractiva para muchas personas, no son tan habituales las publicaciones que ofrecen una mirada global y actualizada de la misma, y mucho menos las pensadas como obras accesibles para un público no especializado.

Ha sido esa dedicación y ese buen hacer los que han acabado situando a Carmen como uno de los referentes más autorizados para hablar de los iberos en los medios, consideración que se ha visto claramente facilitada por sus dotes oratorias. A ella recurre con frecuencia la prensa para contrastar información sobre hallazgos destacados, y en sus declaraciones no ha dudado en manifestar sin corsés sus opiniones respecto a temas polémicos como -por citar los más recientes- los hallazgos ibéricos de la calle Ruaya, en Valencia, que hicieron revivir los anhelos de los sectores conservadores valencianos al respecto de una Tyris ibérica previa a la fundación romana de Valentia; o la falsificación del famoso "vaso de El Campello", cuyo hallazgo fue convertido en mérito institucional por parte de las administraciones competentes cuando todavía no había sido contrastado científicamente. En estos y otros muchos temas Carmen ha ofrecido una visión rigurosa y ajustada a la perspectiva arqueológica, asumiendo esa responsabilidad pública que los historiadores y arqueólogos deben desempeñar ante los usos y los abusos del pasado y del patrimonio.

Lo destacable en su caso es, sin embargo, que ese compromiso público ha ido más allá del patrimonio cultural. Carmen se ha convertido en una gran defensora de la igualdad y de la dignificación y reconocimiento del trabajo de las mujeres en el ámbito académico. Esto le ha llevado, entre otras, a formar parte integrante del activo colectivo Dones Universitàries de la Universitat de València; a presentarse como parte de una candidatura para las elecciones a rectorado de 2010, encabezada por primera vez en la historia de la Universitat de València por una mujer, $\mathbf{M}^{\mathrm{a}}$ Antonia García Benau, y con un claro compromiso por la igualdad; o a enarbolar iniciativas como la recogida de firmas para exigir la dimisión del director de la Real Academia de la Historia, por sus declaraciones sexistas y por los contenidos conservadores y profundamente desactualizados del Diccionario Biográfico Español (2011). Aparte, por supuesto, del papel que ella, como muchas mujeres universitarias, ha desempeñado a través de su propia práctica diaria en la normalización del acceso a cargos de responsabilidad. No en vano, Carmen fue finalista del premio europeo Evelyn Encelot (2001) a propuesta de Francia, como reconocimiento a las mujeres que han destacado en su profesión.

Ese talante y ese compromiso que tanto caracterizan a Carmen son, sin duda, resultado de su propia personalidad. Pero lo cierto es que siempre se ha mostrado orgullosa y agradecida de lo que supuso para ella formarse durante sus años de juventud en un magnífico equipo liderado por Tarradell, donde conocería a dos grandes amigas y compañeras, Mila y Gabi, de las que tanto aprendería (Aranegui 1995 y 2013). Un equipo que además fue clave para el Laboratorio de Arqueología, futuro Departament de Prehistòria i Arqueologia. Recientemente hemos tenido ocasión, junto a otros jóvenes compañeros del Departament, de conocer con cierto detalle ese fascinante momento a través de un proyecto que ha pretendido recuperar la memoria de las arqueólogas del Departament pero que, de alguna manera, ha servido también de homenaje a esas grandes figuras de la arqueología valenciana, entre ellas, evidentemente, la propia Carmen. Con Desmuntant Lara Croft. Dones, Arqueologia i Universitat (Vizcaíno, Machause, Albelda y Real 2014), hemos podido conocer 
más de cerca las vivencias de Carmen durante aquellos años y ello nos ha reafirmado en lo que ya intuíamos, valorándola ya no solo por lo que vemos en el presente a través de nuestro trabajo con ella, sino también por lo que supuso para estar donde estamos.

En ese proceso la figura de Tarradell resulta ineludible. Con la mente abierta y el espíritu conciliador que le caracterizaban, ofreció a Gabi, Mila y Carmen la posibilidad de trabajar en el campo y desarrollar sus propias líneas de investigación. A través de las campañas de La Serreta (Alcoi) y de la Plaza de la Reina (Valencia), de la estrecha colaboración con el SIP, del contacto con los investigadores que venían de fuera y de fructíferos encuentros científicos como los organizados en los cursos de Empúries, Carmen, junto a Mila y Gabi, comenzaron a ser reconocidas por su trabajo, sin que el calificativo de "chicas Tarradell" con el que a menudo eran conocidas fuese obstáculo para que destacasen a título individual en un mundo que seguía estando dominado por hombres. Tras la marcha de Gabi a Brasil (1969) y de Tarradell a Barcelona (1971), el camino del futuro Departament lo marcaron Carmen y Mila, ya doctoras, que en 1986 se convirtieron en catedráticas por la Universitat de València, construyendo así la singularidad valenciana, pues no fue habitual en las universidades españolas que las catedráticas de un departamento fueran exclusivamente mujeres. Este hecho acabó marcando la propia trayectoria del Departament de Prehistòria i Arqueologia, fundado en 1987. Es por ello que debemos ser conscientes de lo que supuso aquel momento y, sobre todo, de lo que ha supuesto Carmen, pues, desgraciadamente, ha sido la única de aquel gran equipo que ha seguido trabajando en este centro.

A su papel en esa etapa tan importante habría que añadir, además, su función como directora del Departament (1993-1996) y de la revista Saguntum-PLAV (2000-2005), para los que apostó por la renovación y la modernidad. Una dedicación que a menudo ha ido más allá, mostrando una clara preocupación e implicación por defender la universidad pública. No debemos olvidar, en este sentido, que Carmen ha participado activamente en momentos clave para la casa, y fue parte integrante de la Comissió d'Estatuts de la Universitat de València (1985).

Así pues, el Departament de Prehistòria i Arqueologia -y pensamos que la Universitat de València en general-, la Arqueología valenciana y, por supuesto, la Arqueología ibérica, tienen mucho que agradecerle. A nosotros, sus compañeros y amigos, nos corresponde seguir aprendiendo de ella, de su vitalidad y del entusiasmo que pone en todo lo que hace.

Por todo, Carmen, gracias.

Valencia, 29 de marzo de 2015

\section{BIBLIOGRAFÍA}

ARANEGUI, C. (1968): Las cerámicas grises de tipo ampuritano en la región valenciana, Memoria de Licenciatura dirigida por Miquel Tarradell, Universitat de València.

ARANEGUI, C. (1972): La cerámica ibérica en la región valenciana, Tesis Doctoral dirigida por Miquel Tarradell, Universitat de València.

ARANEGUI, C. (ed.) (1991): Saguntum y el mar, Conselleria de Cultura, Educació i Ciència, Valencia. 
ARANEGUI, C. (1995): "Recordando a Mila", Homenaje a Milagro Gil-Mascarell Boscá I, Sagvntvm-Plav, 29, 3-4.

ARANEGUI, C. (ed.) (1997): Damas y caballeros en la ciudad ibérica, Cátedra, Madrid.

ARANEGUI, C. (2004): Sagunto, oppidum, emporio y municipio romano, Bellaterra, Barcelona.

ARANEGUI, C. (2012): Los iberos ayer y hoy. Arqueologías y culturas, Marcial Pons, Madrid.

ARANEGUI, C. (2013): "Gabriela Martín Ávila y su contribución a la arqueología alicantina", Arqueología en Alicante: homenaje a Gabriela Martín, Alicante, 21-28.

ARANEGUI, C. (2014): "El momento del cambio: memorias de una experiencia", Desmuntant Lara Croft. Dones, Arqueologia i Universitat, Sagvntvm-Plav Extra-15 (A. Vizcaíno, S. Machause, V. Albelda, C. Real, eds.), 73-78.

VIZCAÍNO, A.; MACHAUSE, S.; ALBELDA, V.; REAL, C. (eds.) (2014): Desmuntant Lara Croft. Dones, Arqueologia i Universitat, Sagvntvm-Plav Extra-15, Valencia. 